\title{
Bat Skin Tumor
}

National Cancer Institute

\section{Source}

National Cancer Institute. Bat Skin Tumor. NCI Thesaurus. Code C134955.

A skin tumor that occurs in a bat. 